\title{
Airway Hyperresponsiveness and Inflammation: Causation, Correlation, or No Relation?
}

\author{
Yvonne MW Janssen-Heininger ${ }^{1}$, Charles G. Irvin², Erich V Scheller ${ }^{3}$, Amy L Brown ${ }^{1}$, Jay K Kolls ${ }^{3}$ and John F Alcorn ${ }^{3 *}$ \\ ${ }^{1}$ Department of Pathology, University of Vermont, Burlington, VT, USA \\ ${ }^{2}$ Department of Medicine, University of Vermont, Burlington, VT, USA \\ ${ }^{3}$ Department of Pediatrics, Children's Hospital of Pittsburgh of UPMC, Pittsburgh, PA, USA
}

\begin{abstract}
Asthma represents a growing problem in the developing world, affecting millions of children and adults. Features of the disease are reversible airflow obstruction, airway hyperresponsiveness and airway inflammation leading to tissue damage and remodeling. Many studies have attempted to address whether inflammation and airway hyperresponsiveness are mechanistically linked. In this study, data are presented from several mouse models that illustrate that a clear link between these features of asthma remains elusive. The impact of altering inflammatory signaling (NF-kB or JNK1) on inflammation and airway hyperresponsiveness was examined. In addition, the effect of antigen sensitization and the route of antigen delivery were investigated. The data herein show that in many cases, inflammation and airway hyperresponsiveness do not directly correlate. In conclusion, the need for mechanistic studies in mouse models is highlighted to address the interplay between these components thought to be critical to asthma pathogenesis.
\end{abstract}

\section{Introduction}

The reactive airway disease, asthma affects millions of people in the United States and worldwide, representing as significant burden on the health care system. The disease pathophysiology includes several hallmark characteristics such as concurring airway inflammation, cytokine production, airway hyperresponsiveness (AHR) to inhaled antigen and subepithelial fibrosis. Both inflammatory (eosinophils, neutrophils, alveolar macrophages, dendritic cells, mast cells, T lymphocytes) and structural (epithelial, fibroblasts, smooth muscle) cell types have been identified as playing a role in the pathogenesis of asthma. Numerous studies in both mice and humans have identified the $\mathrm{T}_{\mathrm{H}} 2$ subset of $\mathrm{T}$ cells as playing a key role in allergic asthma pathogenesis through the production of cytokines and chemokines which induce airway eosinophilic inflammation and AHR. However the direct relationship between inflammation and AHR remains unclear.

Modeling of asthma in mice has been an area of great interest in the last two decades. Most early models relied on antigen sensitization followed by antigen challenge which leads to both inflammation and AHR. The most commonly utilized protocol is the murine ovalbumin (Ova) sensitization and challenge model [1-3]. Mice that have been sensitized and challenged with Ova exhibit increased airway and tissue resistance following methacholine (Mch) challenge, indicative of the development of AHR. In addition, large numbers of eosinophils (and to lesser extent neutrophils) are recruited to the airspaces and mice express increased levels of the $\mathrm{T}_{\mathrm{H}} 2$ cytokines IL-4, IL-5 and IL-13. Several other models have been utilized including antigens from house dust mite, ragweed extract, Aspergillus extract and cockroach extract, all of which producing a similar phenotype to both the Ova model and human asthma. Due to these observations, many have focused on mouse antigen models to understand the complex relationship between AHR and inflammation in the lung.

Several years ago, two conflicting reports were published regarding the mechanistic link between eosinophils and AHR. Using distinct approaches these investigators found either an essential role or little role for inflammation in mouse asthma models [4-5]. Since then, many groups have reported direct correlations between inflammation and AHR and conversely, in some models the two phenotypes appeared unlinked. In the last two years, several studies have shown that genetic manipulation of mice can reduce or increase both AHR and inflammation in a correlative manner [6-9]. Furthermore, exogenous treatment strategies have also been employed with similar results [1011]. In contrast, others have shown that several pharmacologically targeted pathways (histone deacetylase, GSNO reductase, tumor necrosis factor family) can be manipulated to inhibit AHR, but have no effect on lung inflammation [12-14]. These data are further supported by findings in genetically modified mice [15-16]. In summary, the field is confounded by many model dependent findings that reach no clear conclusion as to a direct role for inflammation in driving AHR. The focus of the following studies is to illustrate the complexity of AHR and inflammation data collected in several different mouse model paradigms. First, the impact of inhibiting inflammatory signaling (the NF- $\kappa \mathrm{B}$ or JNK pathways) on the relationship between inflammation and AHR was examined. Next, the effect of antigen sensitization on antigen challenge induced inflammation and AHR was studied. Finally, the route of antigen sensitization was investigated. These individual model paradigms present novel data concerning the relationship between inflammation and AHR.

\section{Methods}

\section{Mice}

For the Ova studies, two to three month old female C57BL/6 mice

*Corresponding author: John F. Alcorn, Department of Pediatrics, Children's Hospital of Pittsburgh of UPMC, One Children's Hospital Dr., 4401 Penn Ave 9127 Rangos, Pittsburgh, PA 15224, USA, Tel: 412-692-7595; Fax: 412-692-5695; E-mail: john.alcorn@chp.edu

Received November 14, 2011; Accepted January 22, 2012; Published January 26, 2012

Citation: Janssen-Heininger YMW, Irvin CG, Scheller EV, Brown AL, Kolls JK, et al. (2012) Airway Hyperresponsiveness and Inflammation: Causation, Correlation, or No Relation? J Aller Ther S1:008. doi:10.4172/2155-6121.S1-008

Copyright: (C) 2012 Janssen-Heininger YMW, et al. This is an open-access article distributed under the terms of the Creative Commons Attribution License, which permits unrestricted use, distribution, and reproduction in any medium, provided the original author and source are credited. 
were purchased from Jackson Laboratories (Bar Harbor, ME). JNK1 -/- mice were generated as previously reported and were backcrossed (> 10 generations) onto the C57BL/6 background [17]. CC10-IкBsr mice were generated as previously reported and were backcrossed (> 10 generations) onto the $\mathrm{BALB} / \mathrm{c}$ background [18]. These mice specifically express a repressor of $\mathrm{NF}-\kappa \mathrm{B}$ activation in CC10 positive airway epithelial cells. All studies utilizing the CC10-IкBsr mice included littermate wild-type controls. For Aspergillus fumigates (Asp) extract studies, two to three month old BALB/c mice were purchased from Taconic Farms (Germantown, NY). All mouse studies were approved by the Institutional Animal Care and Use Committees at the University of Vermont (Ova studies) and the University of Pittsburgh (Asp studies).

\section{Ovalbumin model}

Allergic airway disease was induced as previously reported [19]. Briefly, mice were sensitized with $40 \mu \mathrm{g}$ of Ova with aluminum hydroxide (Alum) adjuvant (Pierce/Thermo Fisher, Rockford, IL) by intraperitoneal (IP) injection on days 0 and 7. Sham-sensitized mice received Alum alone plus vehicle. Beginning on day 14, mice were challenged with $1 \%$ Ova aerosol in sterile PBS for 30 minutes. In the JNK1 -/- studies, mice were challenged for 3 consecutive days and were harvested 48 hours later. In the CC10-IкBsr studies, mice received 6 consecutive days of Ova challenge and were harvested either 48 hours (Figure 2) or 3 weeks (Figure 3) later.

\section{Aspergillus fumigatus antigen model}

For the intratracheal (IT) sensitization studies, mice were sensitized on day 0 and day 7 by IT aspiration of $5 \mu \mathrm{g}$ of Asp allergen extract (Greer, Lenoir, NC) in PBS with no additional adjuvant. On day 14-16, mice were challenged with $5 \mu \mathrm{g}$ of Aspergillus fumigatus allergen extract in PBS by IT administration. On day 17 mice were harvested and analyzed for inflammation and AHR. For the IP sensitization study, mice were sensitized on day 0 and day 7 by IP injection of $20 \mu \mathrm{g}$ of Aspergillus fumigatus allergen extract (Hollister-Stier, Spokane, WA) in PBS along with $4 \mathrm{mg}$ of Imject Alum as an adjuvant. On day 14-16, mice were challenged with $20 \mu \mathrm{g}$ of Aspergillus fumigatus allergen extract in PBS by IT administration, followed by analysis on day 17 .

\section{BAL and differential cell counts}

Following the invasive determination of lung function, mice were lavaged with $1 \mathrm{ml}$ of sterile PBS. Bronchoalveolar lavage (BAL) fluid was spun at $350 \mathrm{x} \mathrm{g}$ to pellet inflammatory cells. Cells were then resuspended in $0.5 \mathrm{ml}$ of sterile PBS and total cell counts were determined by using a hemocytometer. Cytospins were then prepared and stained for differential cell counts. Differential counts were performed by counting cells in a minimum of 5 fields per specimen.

\section{Pulmonary function protocol}

Pulmonary function was assessed by mechanical ventilation (FlexiVent, Scireq, Montreal, QC) of anesthetized $(90 \mathrm{mg} / \mathrm{kg}$ pentobarbital-Na,IP), tracheotomized mice, following intratracheal administration of methacholine. Mice were mechanically ventilated at 200 breaths/min with a tidal volume of $0.2-0.25 \mathrm{ml}$ and a positive end expiratory pressure of $3 \mathrm{~cm} \mathrm{H}_{2} 0$. Respiratory mechanics measurements were then made periodically throughout the experiment. These measurements involved interrupting mechanical ventilation while oscillatory flow signals were applied to the lung by the ventilator. The flow oscillations had amplitudes less than or equal to normal tidal volume and contained small-amplitude frequency components up to $20 \mathrm{~Hz}$. Multiple linear regression was used to fit measured pressure and volume in each individual mouse to the constant phase model of the lung [20-21]. Model fits that resulted in a coefficient of determination less than 0.80 were excluded. From the model, airways resistance $(\mathrm{Rn})$, tissue resistance $(\mathrm{G})$ and tissue elastance $(\mathrm{H})$ were determined. Methacholine was administered as an inhaled aerosol, nebulized in saline solution (up to $50 \mathrm{mg} / \mathrm{ml}$ ) and directed into the lungs via the inspiratory circuit during mechanical ventilation [22].
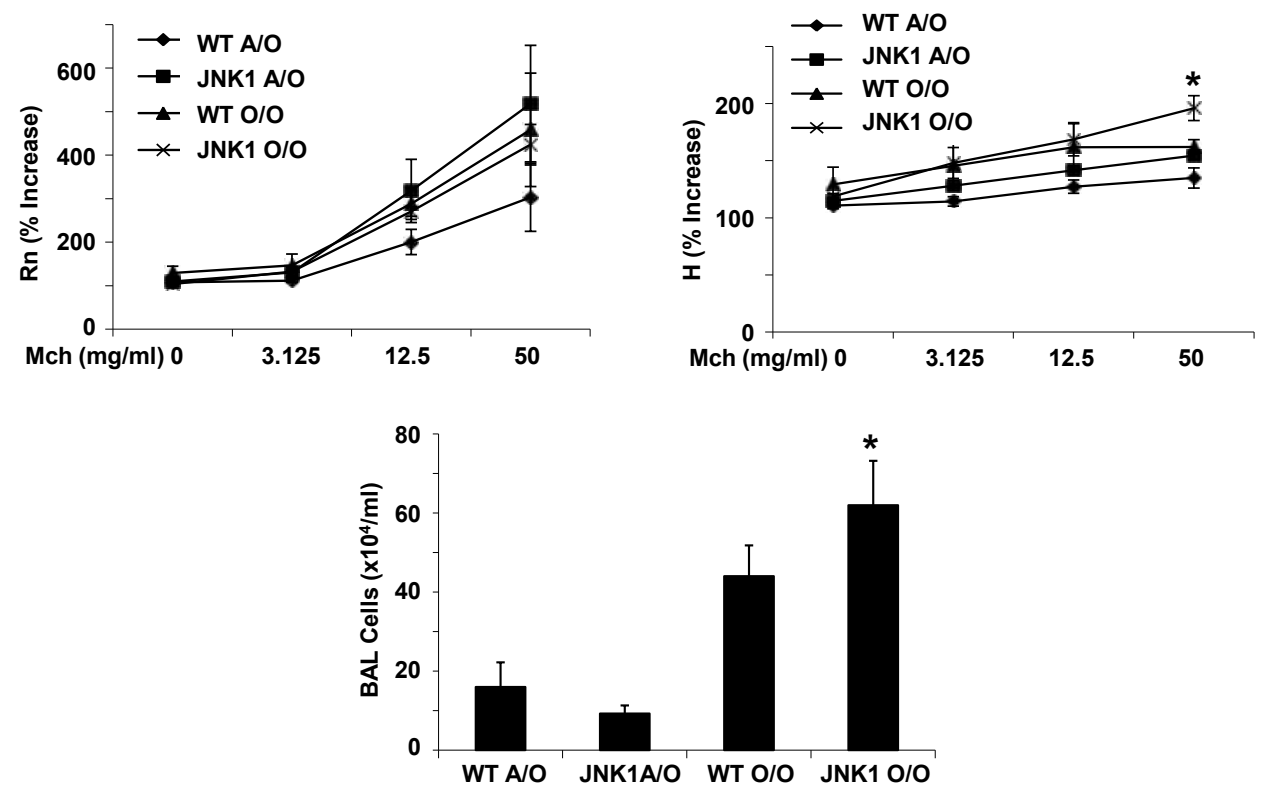

Figure 1: JNK1 suppresses allergic airway inflammation. WT and JNK1 -/- mice were exposed to Ova sensitization and challenge (O/O) or challenge only (A/O) ( $=4,3$ respectively). Top panels, AHR measured by FlexiVent, $\mathrm{Rn}-$ airway resistance, $\mathrm{H}$ - tissue elastance. Lower panel, inflammatory cells in BAL fluid. * $\mathrm{p}<0.05$ versus WT O/O 

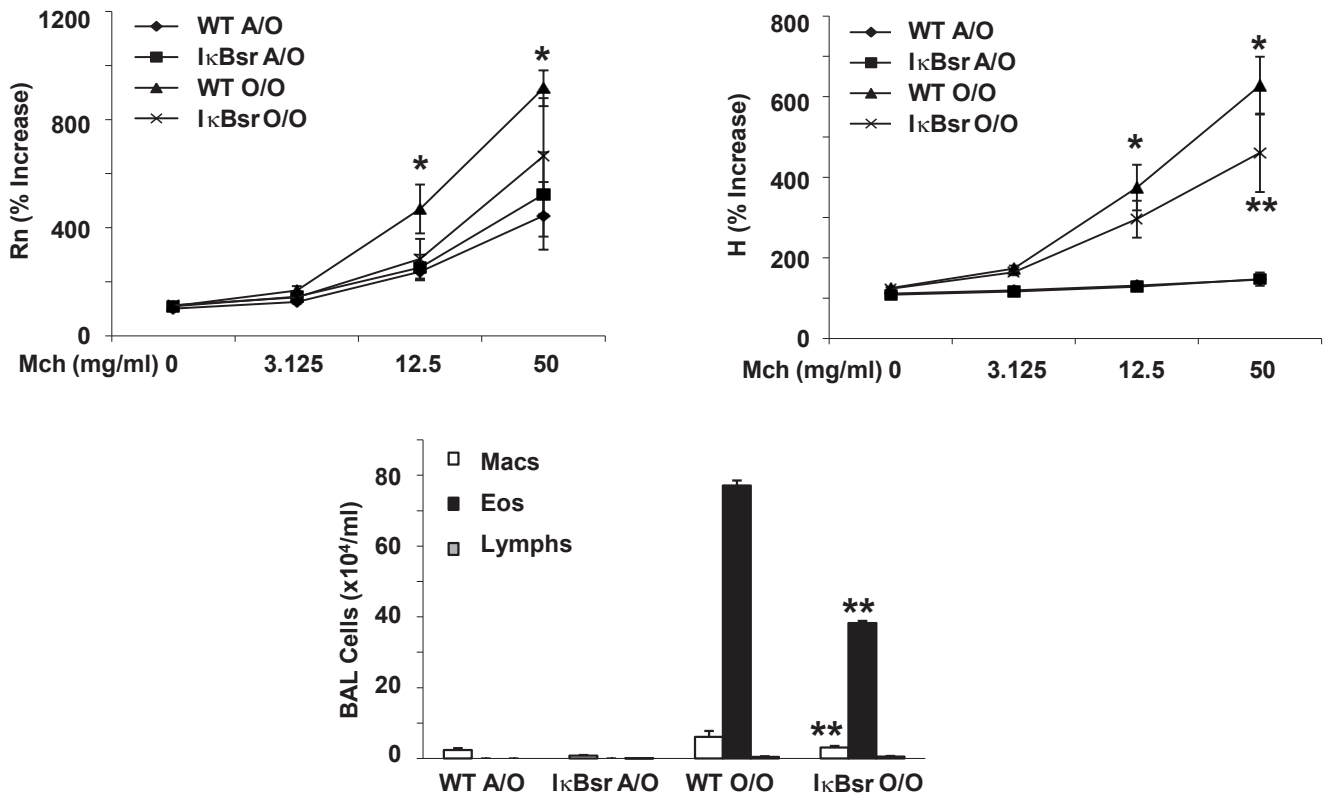

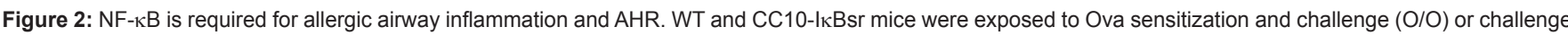
only $(A / O)(n=6,5$ respectively for FlexiVent, $n=8,5$ respectively for cell data), and were analyzed 48 hr after cessation of 6 Ova challenges. Top panels, AHR measured by FlexiVent, Rn - airway resistance, $\mathrm{H}$ - tissue elastance. Lower panel, inflammatory cells in BAL fluid. * $\mathrm{p}<0.05$ versus WT A/O, ${ }^{*} \mathrm{p}<0.05$ versus WT O/O.

\section{Aspergillus allergen-specific immunoglobulin ELISA}

Plates were coated with Asp allergen extract $(2 \mu \mathrm{g} / \mathrm{ml})$ overnight at $4^{\circ} \mathrm{C}$. Plates were then washed and blocked with PBS containing $1 \%$ bovine serum albumin for one hour. Lung homogenate $(50 \mu \mathrm{l})$ was added to each well for two hours at room temperature. After washing, detection antibody (specific for mouse $\operatorname{IgG}_{1}, \operatorname{IgG}_{2 a}$, or IgE) conjugated to HRP was added to each well at a dilution of 1:1000 in blocking buffer for two hours. Antibody binding was visualized by adding TMB substrate for thirty minutes followed by stop solution $\left(2 \mathrm{~N} \mathrm{H}_{2} \mathrm{SO}_{4}\right)$ and reading absorbance at $450 \mathrm{~nm}$.

\section{Statistics}

All data are presented as the mean +/- SEM. Significance was determined by one-way ANOVA followed by Tukey's test for multiple comparisons. Comparisons of two means were conducted using unpaired student's t-test with the assumption of unequal variance. Analyses with a resultant $\mathrm{p}<0.05$ were determined to be significant.

\section{Results and Discussion}

\section{Inflammatory signaling and AHR}

The nuclear factor (NF)- $\mathrm{kB}$ and c-Jun $\mathrm{n}$-terminal kinase (JNK) pathways represent two primary cell signaling cascades involved in the response to lung injury. Both pathways are known to be activated during inflammation and are known to modulate lung responses in the Ova model $[18,23]$. To determine the role of JNK1 in AHR, we exposed wild-type (WT) C57BL/6 and JNK1 -/- mice to inhaled antigen (Ova). We have previously published that JNK1 -/- mice exhibit increased eosinophilic and T cell inflammation compared to WT mice [23]. Consistent with these findings, JNK1 -/- mice had elevated total cell counts in BAL compared to WT mice (Figure 1). Interestingly JNK1 -/mice did not exhibit elevated airway resistance $(\mathrm{Rn})$ versus WT controls.
JNK1 -/- mice did have slightly increased tissue elastance $(\mathrm{H})$ at the highest dose of methacholine tested. Perhaps more intriguing, while both mouse strains displayed high levels of airway eosinophilia, neither had a significant increase in airway resistance and only mild increases in tissue elastance. These data suggest that airway eosinophilia absent of JNK1 activation is not sufficient to drive AHR in the C57BL/6 strain. It has been previously reported that although $\mathrm{C} 57 \mathrm{BL} / 6$ mice recruit elevated eosinophilia versus $\mathrm{BALB} / \mathrm{c}$ mice in response to Ova, $\mathrm{AHR}$ is elevated in the $\mathrm{BALB} / \mathrm{c}$ background to a greater extent than in $\mathrm{C} 57 \mathrm{BL} / 6$ mice [24]. These findings demonstrate a lack of correlation between hyperresponsiveness of the airways and inflammation. To better examine the impact of mouse strain and the relationship between AHR and inflammation, we examined $\mathrm{BALB} / \mathrm{c}$ mice in the following studies.

The NF- $\kappa B$ pathway has been shown to play a key role in promoting airway inflammation in an acute Ova model [18]. In that study, inhibition of NF- $\mathrm{kB}$ in the airway epithelium resulted in a marked suppression of eosinophil recruitment, yet did not alter AHR. To further examine the role of the NF- $\mathrm{BB}$ pathway, WT BALB/c and CC10-IкBsr mice were exposed to prolonged Ova challenged followed by either 48 hours or 3 weeks prior to analysis. Ova induced significant airway eosinophilia and AHR in WT mice (Figure 2). The magnitude of inflammation in $\mathrm{BALB} / \mathrm{c}$ mice was indeed similar to $\mathrm{C} 57 \mathrm{BL} / 6$ mice; however AHR was much greater in the $\mathrm{BALB} / \mathrm{c}$ strain as expected. CC10-IкBsr mice displayed inhibited macrophage and eosinophil recruitment to the lung which correlated with significantly decreased tissue elastance. In this case reduced inflammation correlates with lower airway resistance and tissue elastance. These data are consistent with previous findings that activation of the NF- $\kappa B$ pathway in the airway epithelium results in elevated AHR in the Ova model [25]. In this study, the degree of airway inflammation does indeed correlate with AHR, particularly in the distal lung. Interestingly, CC10-IkBsr mice on the C57BL/6 background did not have attenuated inflammatory 

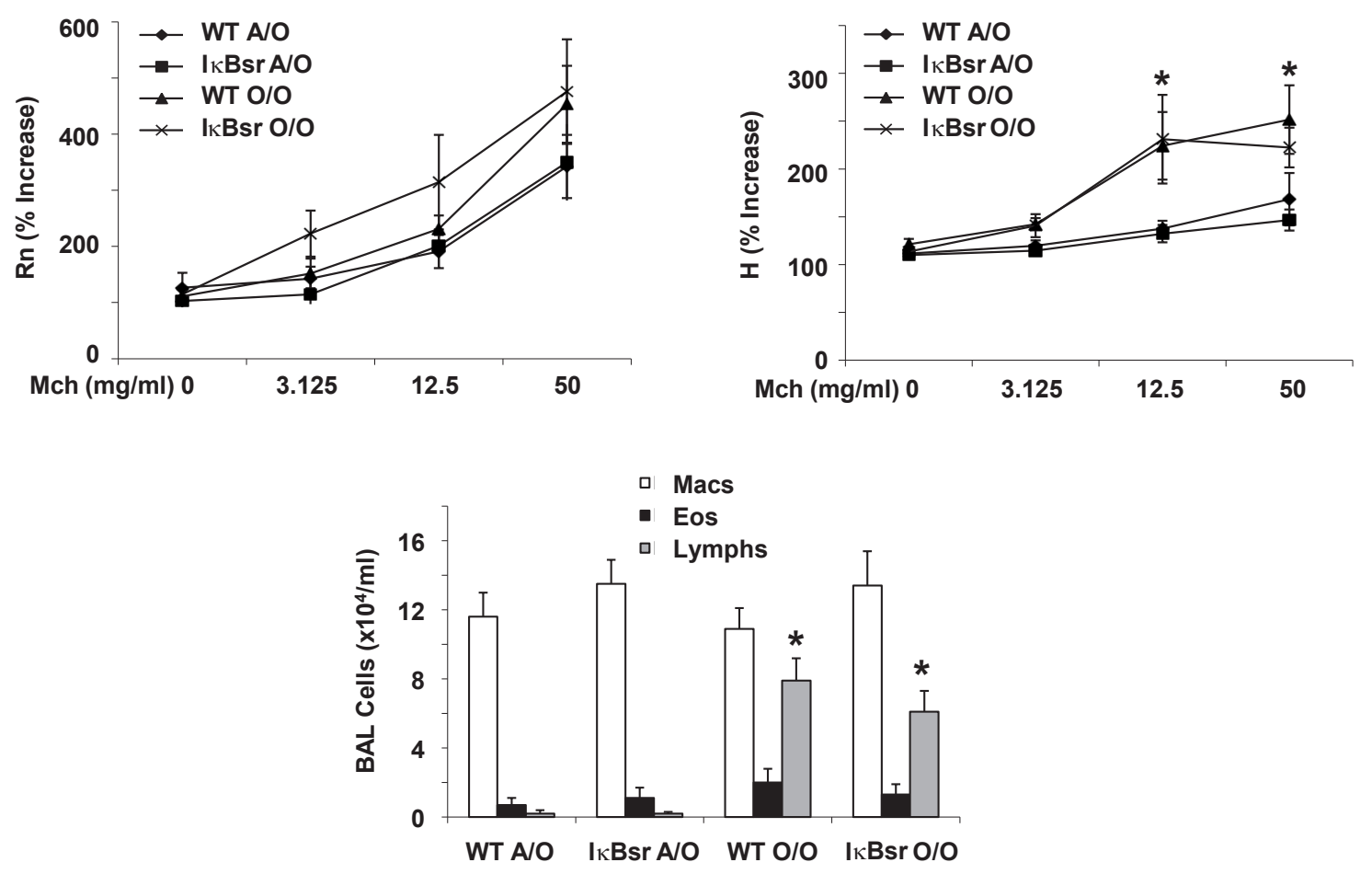

Figure 3: Persistent allergic airway inflammation and AHR three weeks after cessation of 6 antigen challenges. WT and CC10-IкBsr mice were exposed to Ova sensitization and challenge $(O / O)$ or challenge only $(A / O)(n=8,5$ respectively). Top panels, AHR measured by FlexiVent, Rn - airway resistance, $H$ - tissue elastance. Lower panel, inflammatory cells in BAL fluid. ${ }^{*} p<0.05$ versus $A / O$ controls.
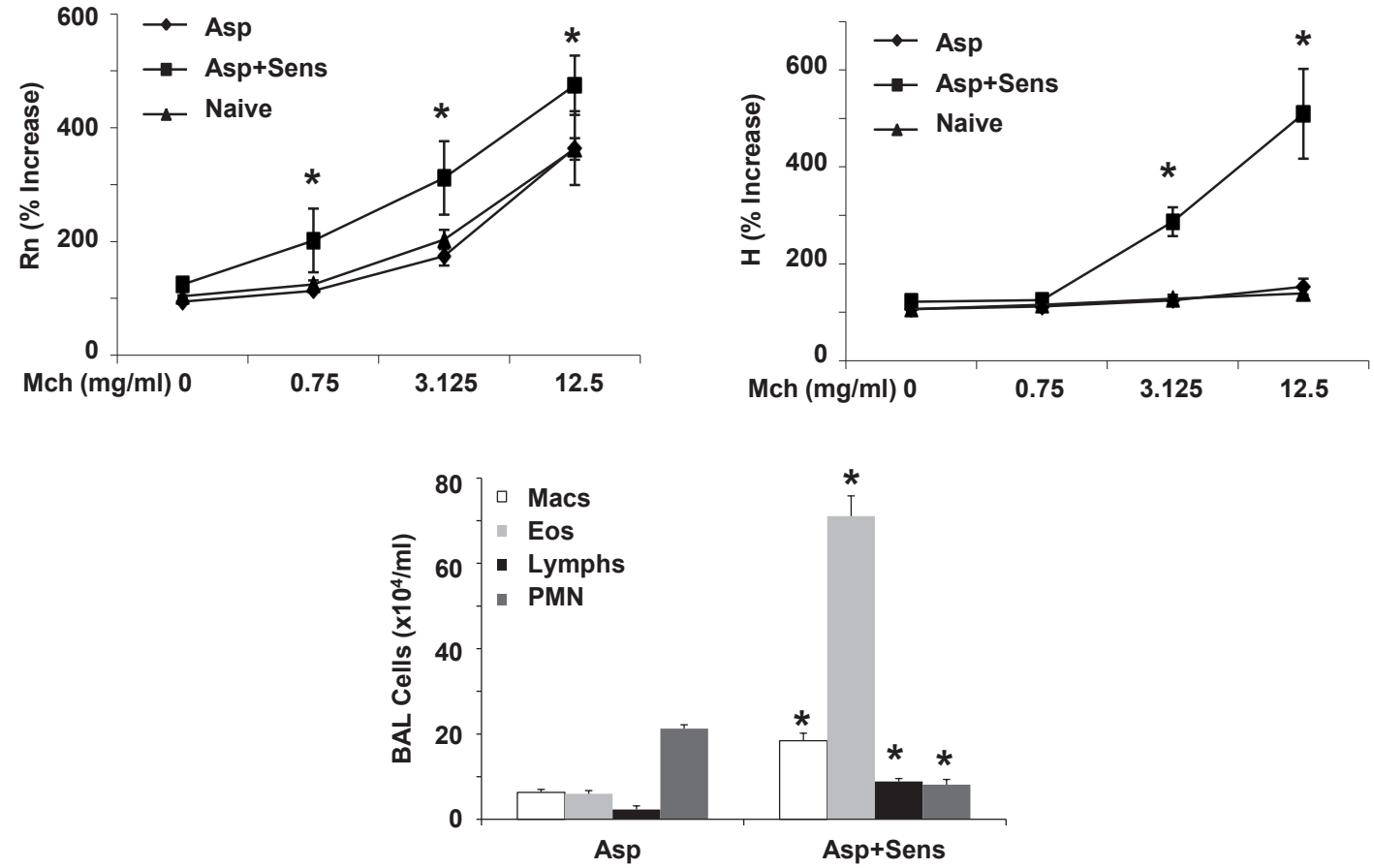

Figure 4: Antigen sensitization promotes AHR and allergic airway inflammation. WT mice were sensitized to Asp (Asp+Sens) or vehicle (Asp) followed by Asp challenge $\left(n=4,3\right.$ respectively, 5 for naïve). Top panels, AHR measured by FlexiVent, $R_{n}$ - airway resistance, $H$ - tissue elastance. Lower panel, inflammatory cells in BAL fluid. * $p<0.05$ versus Asp. 

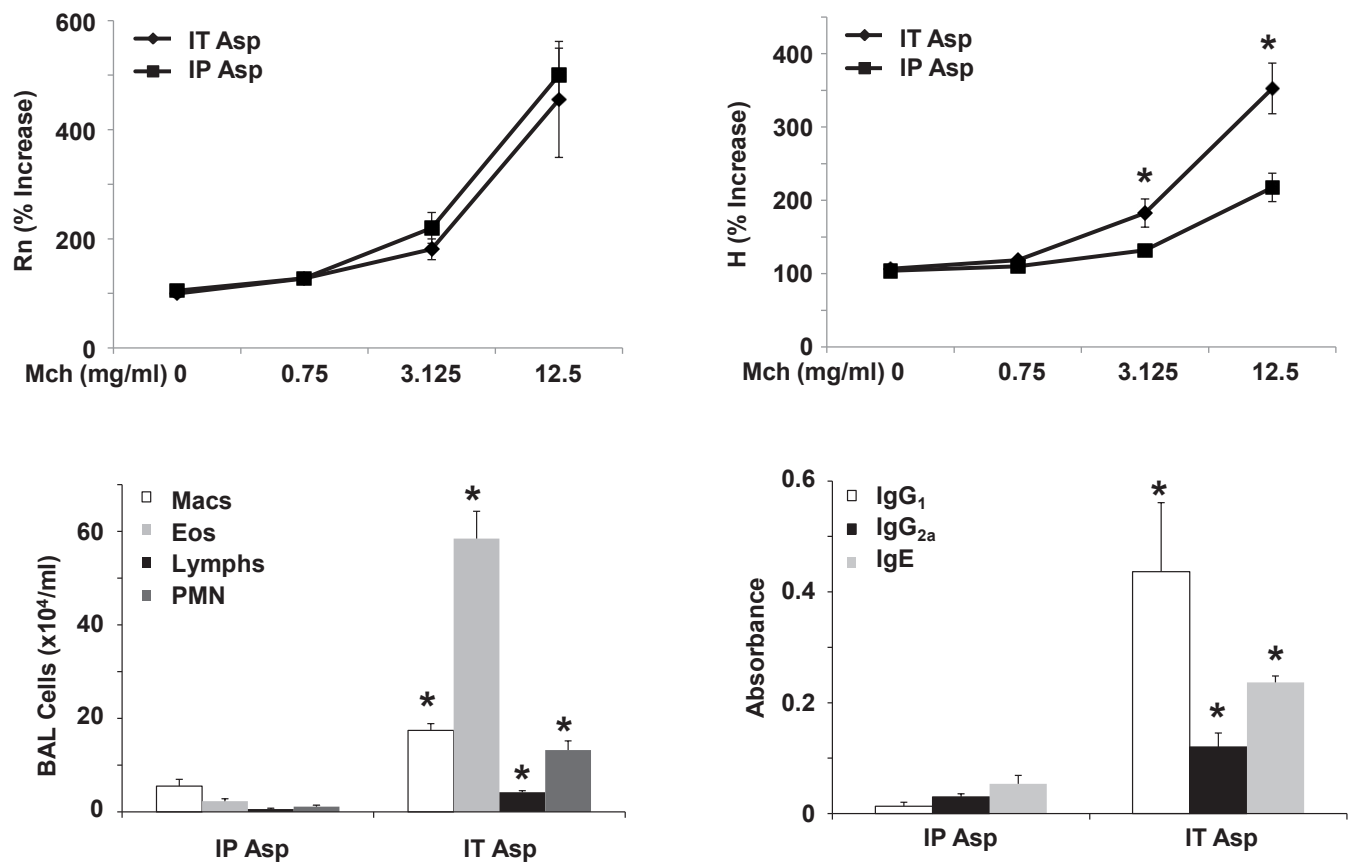

Figure 5: The route of antigen sensitization results in differential inflammatory and AHR responses. WT mice we sensitized to Asp by IT (IT Asp) or IP (IP Asp) administration followed by Asp challenge ( $n=6,8$ respectively). Top panels, AHR measured by FlexiVent, $R$ - airway resistance, $H$ - tissue elastance. Lower panels, inflammatory cells in BAL fluid and Asp specific immunoglobulin in lung homogenate. * $p<0.05$ versus IP Asp.

responses and displayed increased AHR compared to WT littermates [26]. These data illustrate the complexity of interpreting the findings in mouse models of asthma.

Next, we examined the role of the NF- $\mathrm{kB}$ pathway in a chronic Ova model after 3 weeks of recovery from challenge. In this model, airway eosinophilia largely resolves and inflammation is characterized by lymphocytic accumulation in the lung (Figure 3 ). The decrease in airway eosinophilia does indeed correlate with decreased airway resistance, however, Ova-induced tissue elastance increases significantly, indicating that changes in lung elastance may not be related to the presence of eosinophils in the lung. At this time point inhibiting the NF- $\kappa B$ pathway in the airway epithelium did not alter inflammation or AHR when compared to WT mice. These data illustrate that the NF- $\kappa B$ pathway may or may not impact AHR and inflammation depending on the timing of the Ova model utilized. Again, these results demonstrate a lack of a consistent link between eosinophilic inflammation and AHR. Similar data have been previously reported regarding the TGF- $\beta$ pathway and the Ova model. In that study, inhibition of TGF- $\beta$ resulted in increased AHR, but had no effect on lung inflammation [19].

\section{Antigen sensitization and AHR}

Several studies have shown that the route and technique utilized for antigen sensitization may affect the phenotype of allergic airway disease in mice. In addition, many agents induce lung inflammation (such as lipopolysaccharide) without inducing allergic responses. To examine the role of antigen sensitization via the airways on AHR, WT $\mathrm{BALB} / \mathrm{c}$ mice were exposed to Aspergillus fumigates antigen extract (Asp) by intratracheal (IT) exposure. Sensitized mice received Asp on day zero and day seven by IT delivery and where then challenged with Asp for three consecutive days starting on day fourteen. Airway inflammation and AHR were assessed 24 hours later. Control mice received PBS vehicle during sensitization and were then exposed to three Asp challenges. Asp challenge alone induced airway eosinophil and neutrophil recruitment, although sensitized mice displayed significantly higher levels of eosinophils and lower numbers of neutrophils (Figure 4). Asp challenge alone did not induce AHR in $\mathrm{BALB} / \mathrm{c}$ mice, indicating that inflammation alone was not sufficient to promote AHR. Asp sensitization and challenge resulted in marked AHR. These data suggest that inflammation alone is not adequate to drive AHR, but perhaps the magnitude of the allergic response to antigen was critical in generating AHR.

Finally, the impact of the route of antigen sensitization was compared by exposing mice to Asp via IT or intraperitoneal (IP) injection. Asp sensitization via the airway (IT) was much more efficient at eliciting airway inflammation than the IP route (Figure 5). To confirm that IT sensitization generated a greater allergic response than IP sensitization, Asp specific immunoglobulins were measured in lung homogenate. IT Asp did indeed induce significantly higher levels of $\operatorname{IgG}_{1}, \operatorname{IgG}_{2 \mathrm{a}}$ and $\operatorname{IgE}$ compare to IP Asp. However, despite the large difference in airway inflammation and allergic sensitization, both groups displayed similar airway resistance. IT Asp did induce significantly higher tissue elastance compared to the IP Asp group. These data further demonstrate a lack of a direct correlation between AHR and inflammation, using different exposure routes of antigen.

\section{Summary}

The limited examples described above that utilize different models of allergic airway disease, using different time frames, mouse strains, antigens and routes of exposure clearly demonstrate a disparate link between inflammation and AHR. Overall, it can be noted that inflammation perhaps correlates better with tissue elastance changes than airway resistance. This may be due to direct tissue forces related to epithelial cell injury, edema and cellular accumulation in these models and at the least it suggests that the mechanisms of AHR are 
Citation: Janssen-Heininger YMW, Irvin CG, Scheller EV, Brown AL, Kolls JK, et al. (2012) Airway Hyperresponsiveness and Inflammation: Causation, Correlation, or No Relation? J Aller Ther S1:008. doi:10.4172/2155-6121.S1-008

very different axially along the airway tree. Additional evidence for the disjoint of AHR and inflammation has been demonstrated in models of AHR without airway inflammation. Cationic proteins induce AHR without driving inflammation and the A/J strain of mice has spontaneous AHR without airway inflammation [27-28]. In summation, the lack of correlation between inflammation and AHR suggested in the models outlined herein raises the question as to whether these are two mechanistically independent events occurring during allergic airway disease. The subject of the relationship between AHR and inflammation in asthma has been recently reviewed [29]. In that commentary, it is concluded that AHR is likely derived from independent factors that are modulated by inflammation, but are not directly caused by inflammation itself. The numerous examples from the mouse models showing a lack of direct correlation lend support to this argument. Regardless, more mechanistic studies designed to examine the potential causative impact of inflammation on AHR are necessary.

\section{Acknowledgements}

This work was supported by an Unrestricted Research Grant from the American Thoracic Society (JFA), a NIH NHLBI F32 HL082121 (JFA) and NIH R01 HL060014 (YJH) and NIH R01 HL085464 (YJH) and NIH P20 RL15557 (CGI).

\section{References}

1. Bates JH, Rincon M, Irvin CG (2009) Animal models of asthma. Am J Physiol Lung Cell Mol Physiol 297: L401-410.

2. Corry DB, Irvin CG (2006) Promise and pitfalls in animal-based asthma research: building a better mousetrap. Immunol Res 35: 279-294.

3. Irvin CG (2008) Using the mouse to model asthma: the cup is half full and then some. Clin Exp Allergy 38: 701-703.

4. Humbles AA, Lloyd CM, McMillan SJ, Friend DS, Xanthou G, et al. (2004) A critical role for eosinophils in allergic airways remodeling. Science 305: 17761779.

5. Lee JJ, Dimina D, Macias MP, Ochkur SI, McGarry MP, et al. (2004) Defining a link with asthma in mice congenitally deficient in eosinophils. Science 305: 1773-1776.

6. Dittrich AM, Krokowski M, Meyer HA, Quarcoo D, Avagyan A, et al. (2010) Lipocalin2 protects against airway inflammation and hyperresponsiveness in a murine model of allergic airway disease. Clin Exp Allergy 40: 1689-1700.

7. Koh BH, Hwang SS, Kim JY, Lee W, Kang MJ, et al. (2010) Th2 LCR is essentia for regulation of Th2 cytokine genes and for pathogenesis of allergic asthma. Proc Natl Acad Sci U S A 107: 10614-10619.

8. Michel T, Theresine M, Poli A, Domingues O, Ammerlaan W, et al. (2011) Increased Th2 cytokine secretion, eosinophilic airway inflammation, and airway hyperresponsiveness in neurturin-deficient mice. J Immunol 186: 6497-6504

9. Naus S, Blanchet MR, Gossens K, Zaph C, Bartsch JW, et al. (2010) The metalloprotease-disintegrin ADAM8 is essential for the development of experimental asthma. Am J Respir Crit Care Med 181: 1318-1328.

10. Kim SR, Lee KS, Park SJ, Min KH, Choe YH, et al. (2010) Involvement of sirtuin 1 in airway inflammation and hyperresponsiveness of allergic airway disease. $J$ Allergy Clin Immunol 125: 449-460.

11. Qiao J, Li A, Jin X, Wang J (2011) Mastic alleviates allergic inflammation in asthmatic model mice by inhibiting recruitment of eosinophils. Am J Respir Cell Mol Biol 45: 95-100.

12. Banerjee A, Trivedi CM, Damera G, Jiang M, Jester W, et al. (2011) Trichostatin A Abrogates Airway Constriction, but not Inflammation in Mouse and Human Asthma Models. Am J Respir Cell Mol Biol [Epub ahead of print].

13. Doherty TA, Soroosh P, Khorram N, Fukuyama S, Rosenthal P, et al. (2011)
The tumor necrosis factor family member LIGHT is a target for asthmatic airway remodeling. Nat Med 17: 596-603.

14. Foster MW, Yang Z, Potts EN, Foster WM, Que LG (2011) S-nitrosoglutathione Supplementation To Ovalbumin Sensitized and Challenged Mice Ameliorates Methacholine-Induced Bronchoconstriction. Am J Physiol Lung Cell Mol Physiol 301: L739-744

15. Kohan M, Muro AF, Bader R, Berkman N (2011) The extra domain A of fibronectin is essential for allergen-induced airway fibrosis and hyperresponsiveness in mice. J Allergy Clin Immunol 127: 439-446.

16. Masuno K, Haldar SM, Jeyaraj D, Mailloux C, Huang X, et al. (2011) Expression Profiling Identifies KIf15 as a Glucocorticoid Target that Regulates Airway Hyperresponsiveness. Am J Respir Cell Mol Biol 45: 642-649.

17. Dong C, Yang DD, Wysk M, Whitmarsh AJ, Davis RJ, et al. (1998) Defective T cell differentiation in the absence of Jnk1. Science 282: 2092-2095.

18. Poynter ME, Cloots R, van Woerkom T, Butnor KJ, Vacek P, et al. (2004) NF-kappa B activation in airways modulates allergic inflammation but not hyperresponsiveness. J Immunol 173: 7003-7009.

19. Alcorn JF, Rinaldi LM, Jaffe EF, van Loon M, Bates JH, et al. (2007) Transforming growth factor-beta1 suppresses airway hyperresponsiveness in allergic airway disease. Am J Respir Crit Care Med 176: 974-982.

20. Bates JH, Irvin CG (2003) Measuring lung function in mice: the phenotyping uncertainty principle. J Appl Physiol 94: 1297-1306.

21. Hantos Z, Daroczy B, Suki B, Nagy S, Fredberg JJ (1992) Input impedance and peripheral inhomogeneity of dog lungs. J Appl Physiol 72: 168-178.

22. Tomioka S, Bates JH, Irvin CG (2002) Airway and tissue mechanics in a murine model of asthma: alveolar capsule vs. forced oscillations. J Appl Physiol 93 263-270.

23. Alcorn JF, van der Velden J, Brown AL, McElhinney B, Irvin CG, et al. (2009) C-Jun $\mathrm{N}$-terminal kinase 1 is required for the development of pulmonary fibrosis. Am J Respir Cell Mol Biol 40: 422-432.

24. Takeda K, Haczku A, Lee JJ, Irvin CG, Gelfand EW (2001) Strain dependence of airway hyperresponsiveness reflects differences in eosinophil localization in the lung. Am J Physiol Lung Cell Mol Physiol 281: L394-402.

25. Pantano C, Ather JL, Alcorn JF, Poynter ME, Brown AL, et al. (2008) Nuclear factor-kappaB activation in airway epithelium induces inflammation and hyperresponsiveness. Am J Respir Crit Care Med 177: 959-969.

26. Alcorn JF, Ckless K, Brown AL, Guala AS, Kolls JK, et al. (2010) Straindependent activation of NF-kappaB in the airway epithelium and its role in allergic airway inflammation. Am J Physiol Lung Cell Mol Physiol 298: L57-66.

27. Bates JH, Cojocaru A, Haverkamp HC, Rinaldi LM, Irvin CG (2008) The synergistic interactions of allergic lung inflammation and intratracheal cationic protein. Am J Respir Crit Care Med 177: 261-268.

28. Wagers SS, Haverkamp HC, Bates JH, Norton RJ, Thompson-Figueroa JA, et al. (2007) Intrinsic and antigen-induced airway hyperresponsiveness are the result of diverse physiological mechanisms. J Appl Physiol 102: 221-230.

29. Busse WW (2010) The relationship of airway hyperresponsiveness and airway inflammation: Airway hyperresponsiveness in asthma: its measurement and clinical significance. Chest 138: 4S-10S 